\title{
Lysis of the Limiting Membrane of Mycoplasma gallisepticum by Chemical Agents
}

\author{
By H. ZOLA \\ Wellcome Research Laboratories (Biological Division), Beckenham, Kent
}

(Accepted for publication 6 March 1968)

\begin{abstract}
SUMMARY
Lysis of Mycoplasma gallisepticum by various chemical reagents and enzymes was examined. Lysis was measured by determining the release of intracellular constituents, and compared with the results obtained by the turbidimetric method. The ultracentrifuge was used to compare solutions of isolated membrane in 2-chlorethanol, phenol + acetic acid + water mixture, aqueous urea, and aqueous sodium lauryl sulphate, all of which readily dissolved membranes and whole organisms.
\end{abstract}

\section{INTRODUCTION}

Chemical lysis of the limiting membranes of several Mycoplasma species has been studied by Rodwell (1956), Smith \& Rothblat (I960), Razin (1963), Razin \& Argaman (1962, 1963) and Razin, Morowitz \& Terry (1965). These membranes, which are thought to be three-layered lipoprotein membranes (see, for instance, Razin, I963), were readily lysed by surface-active agents, alcohols and a lipase.

As a preliminary to studies of the macromolecules of Mycoplasma gallisepticum, lysis of its enveloping membranes by several chemical reagents was examined. An attempt was made to compare the turbidimetric methods of following lysis used by previous workers with a method which measures the release of intracellular constituents. The ultraviolet spectrum of the cell contents shows an absorption maximum at $260 \mathrm{~m} \mu$, due principally to nucleotide material; this provides a convenient method of determining the cell contents released on lysis. A quantitative index of lysis was sought by using extinction measurements at $260 \mathrm{~m} \mu$. Some mild reagents which lyse the organisms were used to dissolve isolated membranes, and membrane solutions were examined in the ultracentrifuge.

\section{METHODS}

Organism. Mycoplasma gallisepticum strain X95 (PG3I) was grown on Difco PPLO broth supplemented with $20 \%$ normal horse serum and $10 \%(\mathrm{w} / \mathrm{v})$ yeast extract; penicillin and thallium acetate were added to inhibit the growth of other organisms. After incubation at $37^{\circ}$ for 3 days the cultures were concentrated by using a continuousflow M.S.E. centrifuge and the concentrates sedimented at $6000 \mathrm{~g}$ for $30 \mathrm{~min}$. at $2^{\circ}$ in a refrigerated centrifuge (M.S.E. Ltd., London). The sediments were resuspended in sterile phosphate-buffered saline (0.15 M-phosphate, $0.85 \%(\mathrm{w} / \mathrm{v})$ sodium chloride; $\mathrm{pH} 7 \cdot 2$; autoclaved) and recentrifuged three times. The final washed product was a thick paste of organisms containing $17-18 \%$ dry solids. 
Lysis. For the turbidity and ultraviolet absorption experiments organisms were taken up in $\mathrm{M}$-sucrose solution containing sodium chloride $(0.05 \mathrm{M})$ and the suspensions shaken vigorously to break up aggregates. In a typical turbidity experiment a suspension of $8 \mathrm{mg}$. wet organism $/ \mathrm{ml}$. was made and $0.3 \mathrm{ml}$. of solution of lytic agent was added to each $3 \mathrm{ml}$. sample of Mycoplasma suspension. Extinctions were read at $500 \mathrm{~m} \mu$ against appropriate controls after $\mathrm{I} \mathrm{hr}$, the suspensions being shaken before reading. For ultraviolet absorption experiments the concentration of organism was 2-3 $\mathrm{mg}$. wet $/ \mathrm{ml}$. After standing with the reagents for $\mathrm{I} \mathrm{hr}$ at $4^{\circ}$, suspensions were sedimented at $9000 \mathrm{~g}$ for $30 \mathrm{~min}$. at $4^{\circ}$ and extinctions read at $260 \mathrm{~m} \mu$. Proteolysis by pepsin (I mg./ml.) was done in M-sucrose in $0.2 \mathrm{M}$-acetate buffer $\left(\mathrm{pH}^{\circ} \cdot{ }^{\circ}\right)$ for $24 \mathrm{hr}$ at $37^{\circ}$ and the suspensions were then treated as above.

Isolation of cell membranes. Organisms were suspended in de-ionized water and disrupted ultrasonically at $20 \mathrm{Kc}$./sec. (60 W M.S.E.-Mullard ultrasonic oscillator), the disruption being done in an ice water bath. Ultrasonic treatment was followed by centrifugation at $6000 \mathrm{~g}$ for $30 \mathrm{~min}$. at $2^{\circ}$ to remove unbroken organisms; the membranes in the supernatant fluid were then collected by ultracentrifugation at $30000 \mathrm{~g}$.

Ultracentrifugation. This was done with schlieren optics in a Beckman Spinco Model E ultracentrifuge. Double sector optical cells were used to obtain a baseline and thus establish whether curvature was due to the solute or the solvent.

\section{RESULTS}

\section{Qualitative examination of lytic reagents}

Several reagents cleared suspensions of organisms rapidly, requiring no more than visual observation. Thus a suspension of organisms $(5 \mathrm{mg} . \mathrm{wt} / \mathrm{ml}$.) in phosphatebuffered saline was cleared rapidly at room temperature by I-I.5 vol. of phenol + acetic acid +water $(2+\mathrm{I}+0.5, \mathrm{w} / \mathrm{v} / \mathrm{v}$; Rottem \& Razin, 1967), or by $0.5-\mathrm{I}$ vol. of 2-chlorethanol or I vol. of $16 \mathrm{M}$-urea in water. Although when these reagents were used occasional clumps of organisms remained unless the suspension had been very thoroughly shaken before adding the reagent, sodium lauryl sulphate caused complete lysis rapidly and consistently.

Reagents which did not cause rapid or complete lysis were examined with the help of the turbidimetric and ultraviolet absorption methods for following the lysis. The results obtained by the two methods were in agreement qualitatively. Sodium deoxycholate, saponin, digitonin, and a toxin from Staphylococcus aureus (known to possess lipase activity) all resulted in some degree of lysis. Pepsin in acetate buffer $\left(\mathrm{pH}_{3}{ }^{\circ}\right.$ ) caused no more lysis during $24 \mathrm{hr}$ at $37^{\circ}$ than a control solution containing buffer but no enzyme. Aggregation and settling limited the reliability of the turbidimetric method of following lysis, but the ultraviolet absorption method did not suffer from these drawbacks, required only one third as much material, and was more sensitive to small degrees of lysis.

\section{Quantitative comparison of lytic agents}

The ultraviolet adsorption method was used for quantitative studies. Degree of lysis $(\%)$ was expressed in two ways:
(A) $\left(E_{X} / E_{S L S}\right) \times 100$;
(B) $100 \times\left(E_{x}-E_{C}\right) /\left(E_{S L S}-E_{\sigma}\right)$, 
where $E$ denotes the extinction at $260 \mathrm{~m} \mu$, and the suffix $X$ represents the test solution, $C$ the untreated control and $S L S$ the suspension cleared completely by using sodium lauryl sulphate.

Expression (A) is analogous to that used by Razin (1963) in treating turbidimetric results. Expression (B) allows an estimate of the lysis by the reagent after correction for lysis by autolysis or physical handling. The amounts of lysis caused by some chemical reagents are set out in Table $I$.

\section{Table I. Extent of lysis of Mycoplasma gallisepticum,} estimated by extinction at $260 \mathrm{m \mu}$

The concentrations refer to the reaction mixture. $\mathrm{A}=\left(E_{X} / E_{S L S}\right) \times 100$ and $\mathrm{B}=100 \times$ $\left(\mathrm{E}_{X}-E_{C}\right) /\left(E_{S L S}-E_{C}\right)$, where $E$ is the extinction at $260 \mathrm{~m} \mu$ and the suffixes $X, C$ and $S L S$ refer to test solution, untreated control, and sodium lauryl sulphate-treated sample respectively.

Reagent

Sodium lauryl sulphate $0 \cdot 1 \mathrm{M}$

Control

Sodium dexycholate $0.1 \mathrm{M}$

$n$-Butanol $3 \%$

Cetyltrimethylammonium bromide

Saponin $50 \mu \mathrm{g} . / \mathrm{ml}$.

Digitonin $25 \mu \mathrm{g} . / \mathrm{ml}$.

EDTA $0.1 \%$

Magnesium chloride $0.2 \mathrm{M}$

$\begin{array}{rr}\text { A } & \text { B } \\ 100 & 100 \\ 15 & 0 \\ 80 & 75 \\ 30 & 10 \\ 20 & 7 \\ 35 & 25 \\ 35 & 25 \\ 15 & 0 \\ 15 & 0\end{array}$

\section{Preparation of isolated membranes}

To determine the optimum period for ultrasonic treatment, equal samples of a suspension of organisms in de-ionized water were treated ultrasonically for periods from Io sec. to $30 \mathrm{~min}$. An untreated control was used as well as a sample which was completely lysed with sodium lauryl sulphate. The ultraviolet absorptions of the preparations were examined after centrifugation. The results indicated that $20-30 \mathrm{~min}$. ultrasonic treatment was necessary to approach complete lysis. Examination in the electron microscope of a centrifuge pellet $(30,000 \mathrm{~g}$, I hr) obtained after $30 \mathrm{~min}$. ultrasonic treatment indicated that it consisted of membranes which did not appear to be very extensively degraded.

\section{Dissolution of isolated membranes}

Membranes dissolved readily in 0.0 I M-sodium lauryl sulphate in water on shaking. When a solution of approximately Io $\mathrm{mg}$. wet wt membrane/ml. was examined in the ultracentrifuge a single peak was obtained, resembling that obtained by Razin (1967), but the sedimentation coefficient of $2.5 \mathrm{~S}$ was somewhat lower than the value of 3.0 S obtained by Razin.

Solutions of membranes in 2-chlorethanol or $8 \mathrm{M}$-urea in water showed no sedimenting components at rotor speeds up to $59,780 \mathrm{rev} . / \mathrm{min}$. Strongly curving baselines were however observed. A solution in phenol + acetic acid + water $(2+\mathrm{I}+0.5$, $\mathrm{w} / \mathrm{v} / \mathrm{v}$ ) showed several minor fast-moving components, and a strongly curving baseline, at rotor speeds of $40,000 \mathrm{rev} . / \mathrm{min}$. Membrane suspensions did not clear on extensive dialysis against de-ionized water. 


\section{DISCUSSION}

Although results obained by turbidimetry were in qualitative agreement with those obtained by measuring the release of cell contents from the organisms, the latter technique was preferable for the quantitative measurement of lysis. Razin (I964) used an ultraviolet absorption technique in measuring osmotic lysis, which is not accompanied by much membrane dissolution. Lysis by some chemical agents may also occur without dissolution of the membranes; in such cases the turbidimetric method might be misleading.

The bulk of the work done previously on the chemical lysis of Mycoplasma has been concerned with the saprophytic Mycoplasma laidlawii. The present results indicate that the membrane of the parasitic $M$. gallisepticum is qualitatively similar to that of $M$. laidlawii in its behaviour towards various chemical reagents. Membranes dissolved in 2-chlorethanol, urea or phenol + acetic acid + water give patterns with base-lines which show strong curvature at the meniscus and cell bottom, indicating the presence of compounds of low molecular weight. These solvents thus do not appear to produce the same subunits as those obtained using sodium lauryl sulphate, suggesting that the situation may be more complex than that envisaged either by Razin et al. (I965) or by Engelman, Terry \& Morowitz (I967).

The author thanks Mr W. Baxendale (Department of Virology) for growing the Mycoplasma gallisepticum, and Mr P. Laine and Miss L. Sayer for skilled technical assistance.

\section{REFERENCES}

Engelman, D. M., Terry, T. M. \& Morowitz, H. J. (1967), Characterization of the plasma membrane of Mycoplasma laidlawii. Biochim. biophys. Acta 135, 381.

RAZIN, S. (1963). Structure, composition and properties of the PPLO cell envelope. Recent Progress in Microbiology. Ed. by N. E. Gibbons, Symp. Int. Congr. Microbiol. 8, 526. Toronto: University Press.

RazIN, S. (1964). Factors influencing osmotic fragility of Mycoplasma. J. gen. Microbiol. 36, $45 \mathrm{I}$.

RazIN, S. (1967). The cell membrane of Mycoplasma. Ann. N.Y. Acad. Sci. 143, I 5.

RAZIN, S. \& ARGAMAN, M. (I962). Susceptibility of Mycoplasma (PPLO) and bacteria protoplasts to lysis by various agents. Nature, Lond. $193,502$.

Razin, S. \& Argaman, M. (I963). Lysis of Mycoplasma, bacterial protoplasts, spheroplasts, and L-forms by various agents. J. gen. Microbiol. 30, 155 .

RazIN, S., Morowitz, H. J. \& Terry, T. M. (I965). Membrane units of Mycoplasma laidlawii and their assembly to membranelike structures. Proc, natn. Acad. Sci., U.S. 54, 2 I9.

Rodwell, A. W. (1956). The role of serum in the nutrition of Asterococcus mycoides. Aust. J. Bio Sci. 9, 105 .

RotTem, S. \& RAZIN, S. (I967). Electrophoretic patterns of membrane proteins of Mycoplasma. J. Bact. 94, 359.

Sмith,P. F. \& Rothblat, G. H. (1960). Incorporation of cholesterol by PPLO. J. Bact. 8o, 847. 